\title{
Successful difficult airway management using GlideScope video laryngoscope in a child with Cornelia de Lange Syndrome
}

\author{
Sang-Jin Park, Eun Kyung Choi, Suyong Park, Kunjin Bae, Deokhee Lee \\ Department of Anesthesiology and Pain Medicine, Yeungnam University College of Medicine, Daegu, Korea
}

\begin{abstract}
Management of airway in a child with Cornelia de Lange Syndrome (CdLS) should be given due consideration because most of them have the problems related to difficult airway. The GlideScope video laryngoscope can be attempted during routine intubation, however it is mostly used in case of difficulty. With adequate preoperative airway assessment, we used the pediatric video laryngoscope as useful alternative airway device in a child with CdLS and orotracheal intubation proceeded uneventfully.
\end{abstract}

Keywords: Airway; Child; Cornelia de Lange Syndrome

\section{INTRODUCTION}

Cornelia de Lange Syndrome (CdLS) is a rare genetic disease characterized by neurodevelopmental, craniofacial, gastrointestinal, cardiac, and musculoskeletal malformations [1]. Anesthetic management of patients with CdLS should be given due consideration because of unexpected airway problems, including difficult tracheal intubation due to craniofacial anomalies, bronchospasm from hyperactive airways, and aspiration of gastric contents [2-4]. We report a case of successful airway management in a child with CdLS and describe important considerations in anesthetic management.

\section{CASE}

A 5-year-old girl with CdLS, weighing $11.5 \mathrm{~kg}$, was admitted for correction of esotropia. Her preoperative laboratory inves-

Received: December 15, 2017, Revised: January 3, 2018 Accepted: January 9, 2018

Corresponding Author: Eun Kyung Choi, Department of Anesthesiology and Pain Medicine, Yeungnam University College of Medicine, 170, Hyeonchung-ro, Nam-gu, Daegu 42415, Korea

Tel: +82-53-620-3361, Fax: +82-53-626-5275

E-mail: zzini0527@naver.com tigations were normal. The chest radiograph showed no evidence of active lesions, and her electrocardiography (ECG) was normal. She had no previous history of allergies or adverse reaction to drugs. Physical examination revealed a distinctive facial shape with a small head (microcephaly), half-moonshaped unibrows (synophrys), ptosis, and a flat nasal bridge. She was intellectually disabled and uncooperative. She had a short neck with restricted mouth opening and micrognathism.

On arrival to the operating room, her vital signs showed a blood pressure of $92 / 64 \mathrm{mmHg}$, heart rate of 123 beats/min and oxygen saturation of 97\%; her ECG revealed normal sinus rhythm. Anticipating a difficult airway, pre-oxygenation was performed for $5 \mathrm{~min}$. A suction stylet, GlideScope video laryngoscope (Verathon Inc., Burnaby, BC, Canada) and fiberoptic bronchoscope were ready to use in case any difficulty was encountered. Anesthesia was induced with sodium thiopental $75 \mathrm{mg}$ intravenously and continuous infusion of remifentanil (0.1-0.2 $\mu \mathrm{g} / \mathrm{kg} / \mathrm{min})$ followed by rocuronium $10 \mathrm{mg}$ intravenously for muscle relaxation. After $3 \mathrm{~min}$, tracheal intubation was performed on the first attempt with a $4.5-\mathrm{mm}$ endotracheal tube with stylet, using a GlideScope video laryngoscope. Sevoflurane in 50\% oxygen and remifentanil were used to maintain anesthesia. Her vital signs were well maintained intraoperatively. At the end of surgery, pyridostigmine

Copyright (C) 2018 Yeungnam University College of Medicine

This is an Open Access article distributed under the terms of the Creative Commons Attribution Non-Commercial License (http://creativecommons.org/licenses/by-nc/4.0/) which permits unrestricted non-commercial use, distribution, and reproduction in any medium, provided the original work is properly cited. 
$2.3 \mathrm{mg}$ and glycopyrrolate $0.6 \mathrm{mg}$ were administered intravenously for antagonism of muscle relaxation, and once spontaneous breathing was confirmed, the endotracheal tube was gently removed. After extubation, 100\% oxygen was administered with a mask, and after confirming recovery of consciousness and muscle tone, she was transferred to the post-anesthesia care unit. She was discharged on the following day without complications.

\section{DISCUSSION}

CdLS is a rare genetic disorder characterized by mental retardation and distinctive physical anomalies; various systemic medical problems may coexist. Mutations in several genes, including NIPBL gene on chromosome 5, SMC1A on the X chromosome and SMC3 on chromosome 10 are thought to be responsible for this syndrome [5]. The estimated prevalence is 1 in 10,000 to 1 in 30,000, and two-thirds of children with CdLS die within the first year of life [6]. Aspiration-related complications, such as respiratory infection, commonly cause death in early life [3,7].

Difficulty in airway management is the most important consideration in the anesthetic management of a child with CdLS. Appropriate management of airway problems is crucial, as they can lead to serious morbidity and mortality. Presence of cleft palate, micrognathia, macroglossia, protruding teeth, and short neck may complicate airway management in a child with CdLS [2,3]. Our patient had a distinctive facial appearance characterized by microcephaly, synophrys, ptosis, flat nasal bridge, short neck, and restricted mouth opening with micrognathia. Preoperative airway assessment including Mallampati classification was tried, but was limited as the child was poorly cooperative. When difficulty in airway management is anticipated, alternative airway devices including laryngeal mask airway, video laryngoscope, and flexible fiberoptic bronchoscope should be readily available to prevent a disastrous airway compromise.

Although video laryngoscopy can be attempted during routine intubation, it is mostly used in case of difficulty. Recently, the video laryngoscope has been commonly available for management of difficult airways in pediatric anesthetic practice. When visualization of the larynx is difficult due to limited neck movement, restricted mouth opening, or a mass on the floor of the mouth, a video laryngoscope can provide a supe- rior laryngoscopic view [8,9]. Many reports describe successful tracheal intubation using the video laryngoscope in children with a difficult airway [10,11]. Generally, tracheal intubation in children is more challenging than tracheal intubation in adults, owing to unique airway characteristics, including a more cephalad larynx, restricted mouth opening [12], and a relatively higher oxygen consumption, allowing limited time for intubation [13]. Moreover, successful intubation on the first attempt is especially important in children with a potentially difficult airway as in our patient. Although flexible fiberoptic bronchoscopy is considered the most important device for managing anticipated difficult airways, many anesthesiologists prefer using a video laryngoscope due to ease of use. Therefore, we used the pediatric video laryngoscope at the outset and intubation proceeded uneventfully.

Besides management of possible difficult intubation, children with CdLS have highly sensitive airways, frequently leading to laryngospasm or bronchospasm soon after exposure to volatile anesthetics or following tracheal intubation $[4,14]$. Additionally, they have a high risk of vomiting or aspiration because of poor esophageal motility and gastroesophageal reflux [15]. Significant comorbidities, such as ventricular septal defects, pulmonary hypertension, seizures, peripheral neuropathy, behavioral issues, renal malformation, and vesicoureteral reflux, may coexist [6]. Hence, anesthetic management should be planned based on the patient's clinical condition related to underlying medical history as well as airway assess- ment.

In conclusion, the video laryngoscope may be a useful device for orotracheal intubation in the airway management of children with CdLS. Moreover, adequate preoperative airway assessment and availability of alternative intubation methods and airway devices are crucial to prevent disastrous airway compromise.

\section{CONFLICT OF INTEREST}

No potential conflict of interest relevant to this article was reported.

\section{ORCID}

Sang-Jin Park, https://orcid.org/0000-0002-4838-2664

Eun Kyung Choi, https://orcid.org/0000-0001-5758-6741

Deok Hee Lee, https://orcid.org/0000-0003-2072-7576 


\section{REFERENCES}

1. Corsini LM, De Stefano G, Porras MC, Galindo S, Palencia J. Anaesthetic implications of Cornelia de Lange syndrome. Paediatr Anaesth 1998;8:159-61.

2. Tsukazaki Y, Tachibana C, Satoh K, Fukada T, Ohe Y. A patient with Cornelia de Lange syndrome with difficulty in orotracheal intubation. Masui 1996;45:991-3.

3. August DA, Sorhabi S. Is a difficult airway predictable in Cornelia de Lange syndrome? Paediatr Anaesth 2009;19:707-9.

4. Takeshita T, Akita S, Kawahara M. Anesthetic management of a patient with Cornelia De Lange syndrome. Anesth Prog 1987;34:63-5.

5. Vincent MV, Duncan ND. Gastroesophageal reflux and reflux oesophageal strictures in children with Cornelia de Lange syndrome. West Indian Med J 2013;62:161-4.

6. Schrier SA, Sherer I, Deardorff MA, Clark D, Audette L, Gillis $\mathrm{L}$, et al. Causes of death and autopsy findings in a large study cohort of individuals with Cornelia de Lange syndrome and review of the literature. Am J Med Genet A 2011;155A: 3007-24.

7. Luzzani S, Macchini F, Valadè A, Milani D, Selicorni A. Gastroesophageal reflux and Cornelia de Lange syndrome: typical and atypical symptoms. Am J Med Genet A 2003;119A:283-7.

8. Torres MD, Calvo E, Fernández Esplá F, Gilsanz F. Anes- thetic management of an adult patient with Cornelia de Lange Syndrome. Minerva Anestesiol 2010;76:229-31.

9. Stavinoha RC, Kline AD, Levy HP, Kimball A, Mettel TL, Ishman SL. Characterization of sleep disturbance in Cornelia de Lange Syndrome. Int J Pediatr Otorhinolaryngol 2011;75: 215-8.

10. Stevic M, Milojevic I, Bokun Z, Simic D. Unpredictable drug reaction in a child with Cornelia de Lange syndrome. Int J Clin Pharm 2015;37:1-3.

11. Fernández-García R, Pérez Mencía T, Gutiérrez-Jodra A, López García A. Anesthetic management with laryngeal mask in a child with Brachmann-de Lange syndrome. Paediatr Anaesth 2006;16:698-700.

12. Tsukahara M, Okamoto N, Ohashi H, Kuwajima K, Kondo I, Sugie H, et al. Brachmann-de Lange syndrome and congenital heart disease. Am J Med Genet 1998;75:441-2.

13. Kline AD, Krantz ID, Sommer A, Kliewer M, Jackson LG, FitzPatrick DR, et al. Cornelia de Lange syndrome: clinical review, diagnostic and scoring systems, and anticipatory guidance. Am J Med Genet A 2007;143A:1287-96.

14. Washington V, Kaye AD. Anesthetic management in a patient with Cornelia de Lange syndrome. Middle East J Anaesthesiol 2010;20:773-8.

15. Papadimos TJ, Marco AP. Cornelia de Lange syndrome, hyperthermia and a difficult airway. Anaesthesia 2003;58:924-5. 